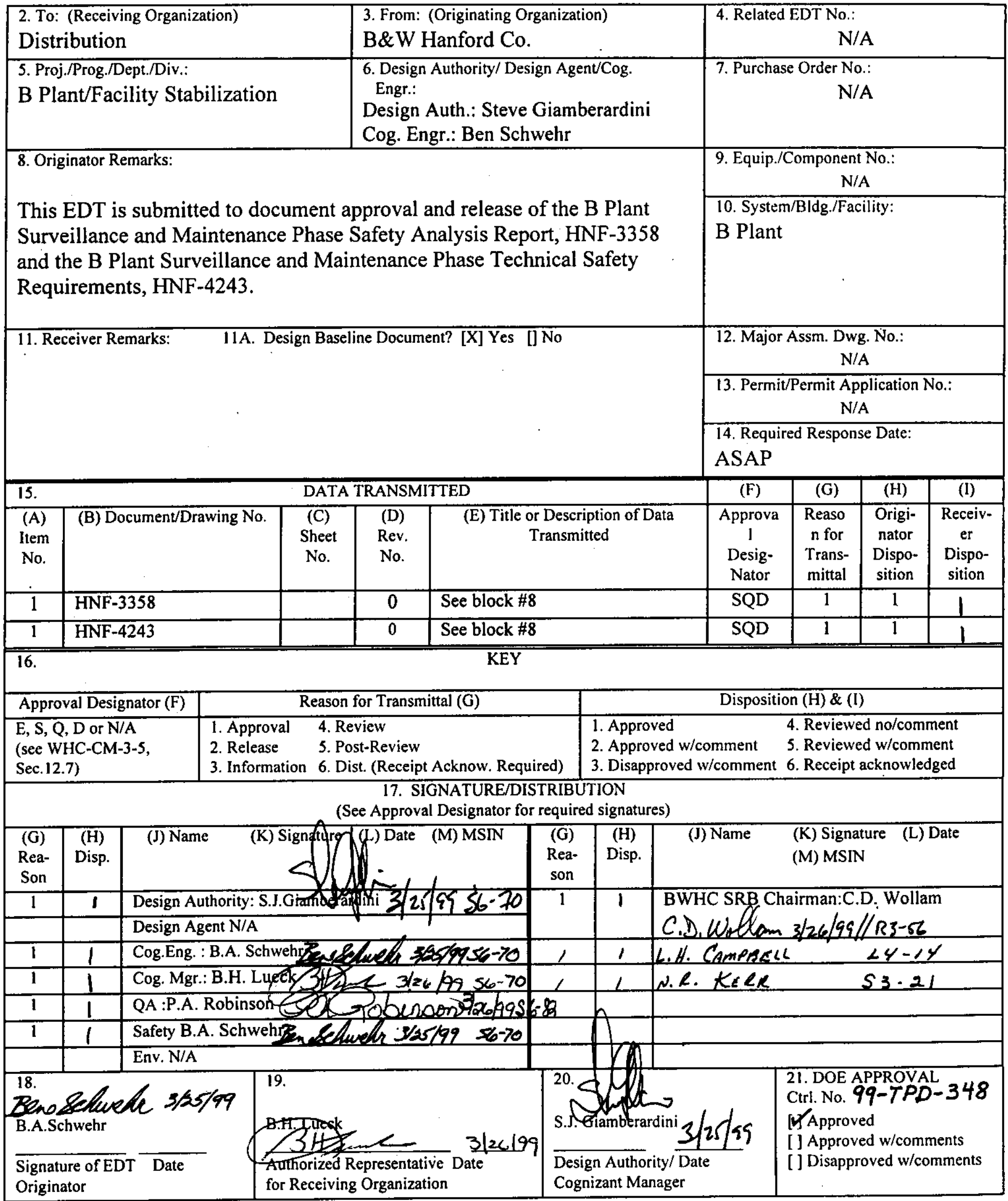


HNF-4243, Rev. 0

$\int$

\section{B PLANT SURVEILIANCE AND MAINTENANCE PHASE TECHNICAL SAFETY REQUIREMENTS}

B. A. Schwehr

B\&W Hanford Company, Richland, WA 99352

U.S. Department of Energy Contract DE-AC06-96RL13200

EDT: $625891 \quad$ UC: 510

Org Code: 16A00 Charge Code: 101242

BER Code: EW7050000 Total Pages: 15

Key Words: B Plant, Safety Analysis Report (SAR), Accident Analysis, Safety Equipment, Safety Class, Safety Significant, Technical Safety Requirement, Administrative Control, Worker Protection.

Abstract: This document identifies administrative controls that are established for the operating contractor of the $B$ plant facility during the $B$ Plant surveillance and maintenance phase. When approved by the DOE-RI, this document is part of the $B$ Plant safety authorization basis.

Look for the associated B Plant Surveillance and Maintenance Phase Safety Analysis Report, HNF-3358.

TRADEMARK DISCLAIMER. Reference herein to any specific commercial product, process, or service by trade name,
trademark, manufacturer, or otherwise, does not necessarily constitute or imply its endorsement, recommendation, ot trademark, manufacturer, or otherwise, does not necessarliy constitute or lmply its endorsement, recommendati

Printed in the United States of America. To obtain copi

Box 950, Mailstop H6-0B, Richiand WA 99352, Phone (509)
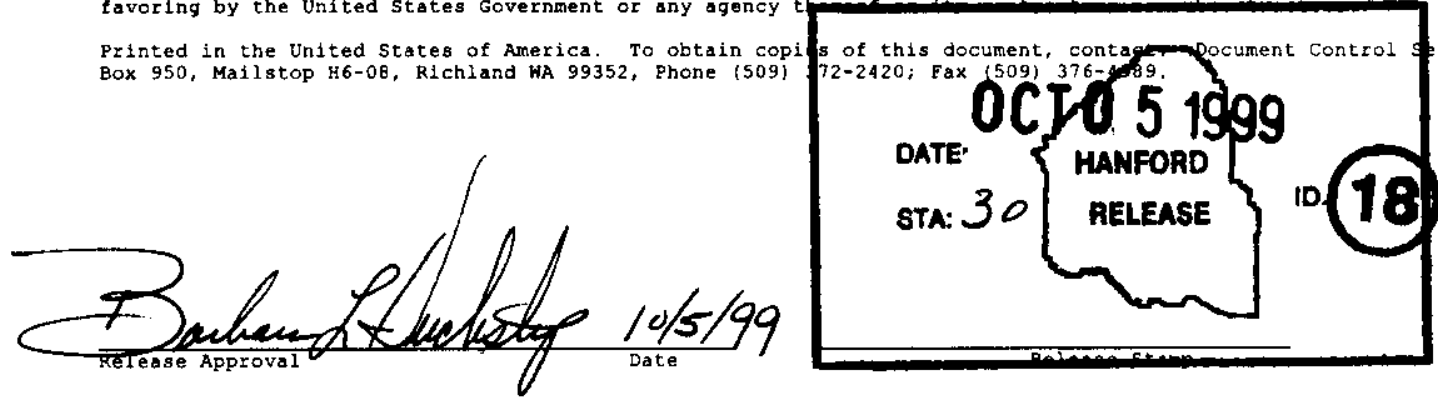

\section{Approved for Public Release}




\section{B PLANT}

\section{SURVEILLANCE \& MAINTENANCE PHASE TECHNICAL SAFETY REQUIREMENTS}

B \& W HANFORD COMPANY

AUGUST 1999

For the U.S. Department of Energy 
HNF 4243 Rev. 0

This page intentionally left blank. 


\section{PREFACE}

This document contains the Technical Safety Requirements (TSRs) for the B Plant Facility (B Plant). B Plant is deactivated and is operating in a Surveillance and Maintenance (S\&M) Phase.

The B Plant S\&M Phase mission is to safely conduct surveillance and maintenance activities to control the remaining hazards and hazardous materials at B Plant, thereby protecting the environment, the public, and the Hanford site and facility workers.

The B Plant TSRs define management and/or administrative controls required to ensure safe B Plant operation during the S\&M Phase. The TSRs are based on preventive features determined to be essential in the B Plant Surveillance and Maintenance Phase Safety Analysis Report, HNF-3358, Rev. 0 (BWHC 1999) (B Plant S\&M Phase SAR: prevent accidents with significant consequences. Bases are provided for the controls anu associated parameters.

The format and content of these TSRs are based on DOE Order 5480.22 Technical Safety Requirements and DOE Standard DOE-STD-3009-94, Preparation Guide for U.S. Department of Energy Nonreactor Nuclear Facility Safety Analysis Reports (DOE 1994). The format and content guidelines of the Project Hanford Management Contract procedure Safety Analysis and Technical Safety Requirements, HNF-PRO-700, Rev. 1 (FDH 1997) were used in developing this document. The terms, definitions, notations and requirements specified in the Use and Application section (Section 1.0 of this document) are presented as established in FDH 1997.

These TSRs constitute an agreement or contract between DOE and Fluor Daniel Hanford, Inc. regarding the safe operation of B Plant. As such, they cannot be changed without the Cognizant Secretarial Officer (CSO) or designee approval.

\section{INTRODUCTION AND GENERAL FACILITY DESCRIPTION}

B Plant is located in the 200 East Area of the Hanford Nuclear Reservation in Washington state. The B Plant Facility is an arrangement of buildings, structures, and systems that were used for various missions before being shut down and deactivated in the late 1990s. The B Plant facility is described in the B Plant S\&M Phase SAR. Two of the major B Plant structures, the $221 \mathrm{~B}$ canyon building and the retired filter vaults in the $291 \mathrm{~B}$ area, are major participating structures in the B Plant TSRs.

B Plant currently has no purpose or operations beyond safely storing the residual radioactive and hazardous materials contained in the deactivated structures. B Plant does not rely on processes provided by other Hanford facilities nor does B Plant support other facilities processes or missions. B Plant's TSRs do not involve other facilities, nor do other facilities' TSRs involve B Plant. B Plant is immediately adjacent to the Waste Encapsulation and Storage Facility (WESF). WESF has its own safety authorization basis and associated TSRs. 
HNF 4243 Rev. 0

\section{FACILITY STATUS}

B Plant is deactivated, but contains a significant amount of residual radioactive material in the 221B Canyon Building and the deactivated/retired High Efficiency Particulate (HEPA) Filters. These HEPA filters were taken out of service while deactivating the facility. The filters are isolated from the buildings they served and from the fans and stack of the deactivated system. There are other buildings with less significant residual radioactive material. The B Plant radioactive residual material estimated inventories are shown in Table 3.3-3 of the SAR. There are no significant quantities of residual chemical or hazardous waste materials at B Plant. The remaining chemical and hazardous materials at B Plant do not present significant hazards to the environment, the public, or the Hanford site and facility workers.

B Plant is a Hazard Category 2 nuclear facility, based on the remaining radioactive material inventory, as described in the B Plant S\&M Phase SAR, Section 3.3. The S\&M Phase mission involves monitoring the facility and associated residual materials and hazards to prevent uncontrolled releases.

\section{TSRs SUMMARY}

There are no Technical Safety Requirements with Safety Limits (SLs), Limiting Control Settings (LCSs), Limiting Conditions for Operations (LCOs), or Surveillance Requirements (SRs). There are three TSRs that have Administrative Control to establish safe boundaries for the most significant hazards at B Plant during the S\&M Phase. These hazards are associated with worker protection from radiological and occupational hazards, consequences initiated by uncontrollable natural phenomena, and administrative/management and safety programs. 
TABLE OF CONTENTS

PREFACE

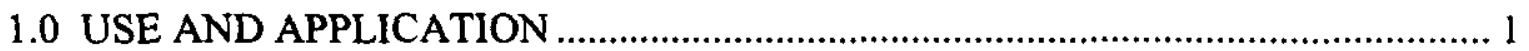

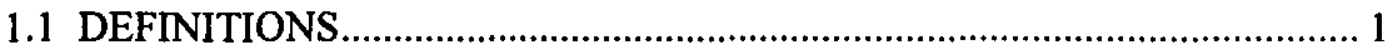

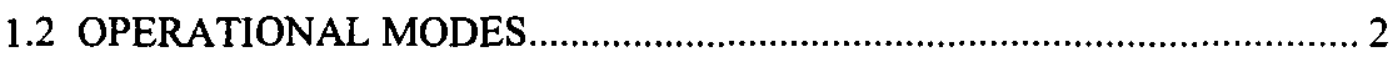

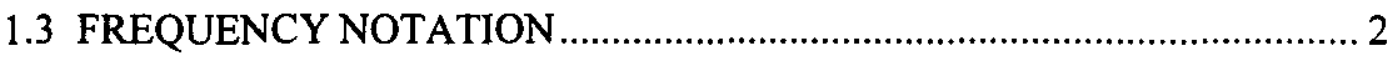

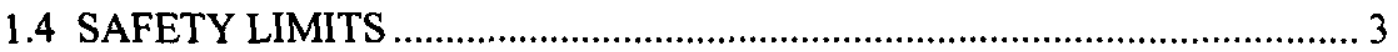

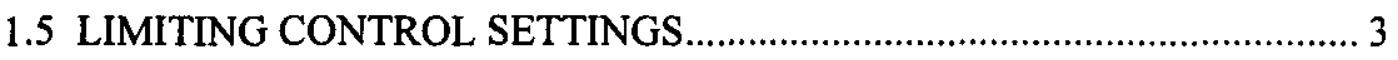

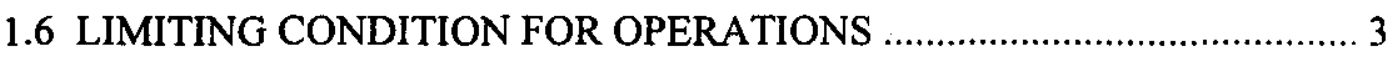

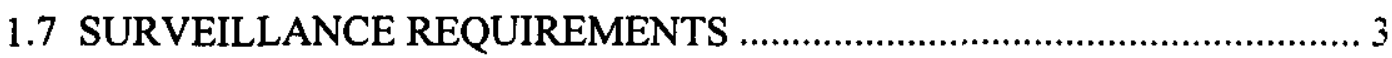

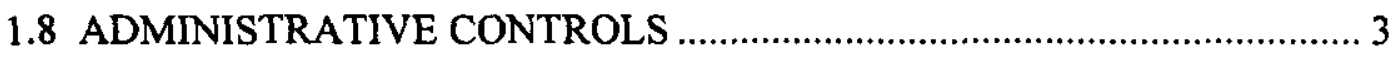

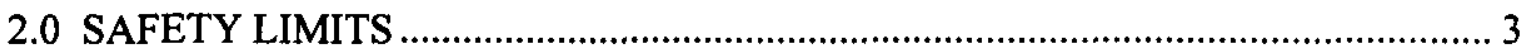

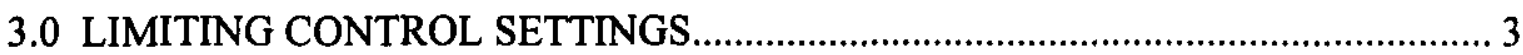

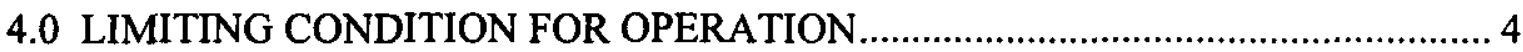

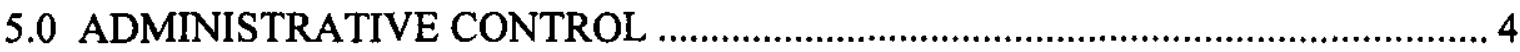

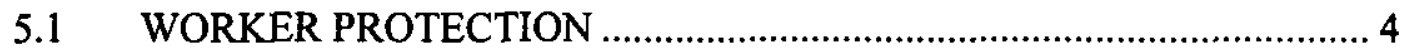

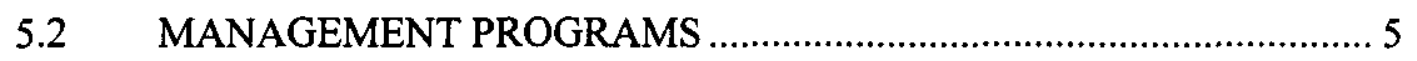

5.3 OPERATIONS EXPECTATIONS/PROGRAMS ……........................... 6

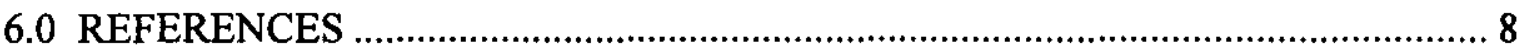


HNF 4243 Rev. 0

This page intentionally left blank. 


\subsection{USE AND APPLICATION}

This section defines terms used in a TSR and explains the use and application of the terms.

\subsection{DEFINITIONS}

Specific terms that have special definitions and are used in the TSRs are defined in this section. Each TSR does not contain a "definitions" section. When terms that are defined in this section are used in the TSR, they appear in all-capitalized type.

\section{EXTENSION}

Where a specific activity, such as a surveillance requirement, must be performed on a specified routine interval, there is a maximum allowable extension of $25 \%$ of the interval. This extension is intended to provide operational flexibility and should not be relied upon as a routine extension of the specified interval

\section{FREQUENCY NOTATION}

A frequency notation is a term established to define a specific frequency. This frequency notation is then applied to a specific activity, such as a surveillance activity. See the definition of "QUARTERLY".

\section{LIMITING CONDITION FOR OPERATIONS (LCO)}

An LCO specifies limits that represent the lowest functional capability of performance level of safety-related items required for the safe operation of a facility.

\section{LIMITING CONTROL SETTING (LCS)}

An LCS is a limit established for a safety system process variable to prevent exceeding the associated safety limit.

\section{OPERATIONAL MODES}

Operational mode is a term established to define a specific mode where the specific activities or types of activities are defined and authorized.

\section{QUARTERLY}

This is the established and required frequency at which an activity must be performed or the duration between which the activity is performed. Quarterly means 92 calendar days. See the definition of "EXTENSION". 


\section{RETIRED FILTER VAULTS}

The retired filter vaults are the vaults of the deactivated canyon ventilation system that contain HEPA filters with considerable quantities of residual radioactive materials. The vaults are located underground about 30 to 50 meters south of the east end of the 221B canyon building. This area is sometimes called the 291B area, because the structures in this area are numbered as 291BA through 291BG.

\section{SAFETY LIMIT (SL)}

A safety limit is a limit on process variables associated with those passive physical barriers that are necessary for the intended facility function and that are required to guard against the uncontrolled release of radioactive or other hazardous materials.

\section{SURVEILLANCE REQUIREMENT}

This is a requirement defining specific actions and frequencies thereof, to test, calibrate, and/or inspect/assess the operability and quality of safety related items or the quality of conditions required for the safe operation of a facility.

\subsection{OPERATIONAL MODES}

Each TSR specifies an operational mode that is specific to the portion of the TSR where the operational mode is specified. This section defines the B Plant operational mode that will be specified in the TSRs. There are two operational modes for B Plant. They are defined as follows:

OPERATION Activities being performed are anticipated and authorized for the facility mission by the SAR approval and/or a current campaign is being performed in accordance with authorization documentation separate from the SAR approval. This mode involves the surveillance and maintenance activities explicitly and implicitly implied by the B Plant S\&M Phase SAR.

RESTRICTED Activities being performed are conducted in accordance with authorization documentation for operating under abnormal facility conditions, other than the conditions of the OPERATION mode defined above.

\subsection{FREQUENCY NOTATION}

Each TSR specifies a frequency notation that is specific to the portion of the TSR where the frequency notation is specified. This section identifies the B Plant frequency notation(s) that will be specified in the TSRs. 
There is only one frequency notation applicable to the B Plant TSRs. A surveillance of the hydrogen concentration and configuration of the passive vent system is to be performed QUARTERLY. See the definition of "QUARTERLY" in the "Definitions" section.

\subsection{SAFETY LIMITS}

There are no Safety Limits associated with B Plant TSRs, therefore this term is defined, but is not explained.

\subsection{LIMITING CONTROL SETTINGS}

There are no Limiting Control Settings associated with B Plant TSRs, therefore this term is defined, but is not explained.

\subsection{LIMITING CONDITION FOR OPERATIONS}

There are no Limiting Conditions for Operations associated with B Plant TSRs, therefore this term is defined, but is not explained.

\subsection{SURVEILLANCE REQUIREMENTS}

There are no Surveillance Requirements associated with B Plant TSRs, therefore this term is defined, but is not explained.

\subsection{ADMINISTRATIVE CONTROLS}

Administrative controls are provisions relating to organization and management, procedures, record keeping, assessments, and reporting necessary to ensure safe operation of the facility.

Administrative controls (ACs) are established where a control is necessary to ensure a significant hazard is prevented or mitigated by means other than a SL, LCS, LCO, or SR or institutional safety requirements. An example of this is an AC for B Plant that establishes worker protection from hazards associated with the roof collapse and DBE. Another example of an AC that is applied for B Plant is an AC that establishes a staffing requirement to fulfill safety programs and operating commitments.

\subsection{SAFETY LIMITS}

There are no Safety Limits associated with operating B Plant during the S\&M Phase.

\subsection{LIMITING CONTROL SETTINGS}

There are no Limiting Control Settings associated with operating B Plant during the S\&M Phase. 
HNF 4243 Rev. 0

\subsection{LIMITING CONDITION FOR OPERATION}

There are no Limiting Conditions for Operation associated with operating B Plant during the S\&M Phase.

\subsection{ADMINISTRATIVE CONTROL}

The following administrative controls have been developed for B Plant during the surveillance and maintenance phase.

\subsection{WORKER PROTECTION}

\subsubsection{Requirement for Worker Protection}

A program shall be established, implemented and maintained for worker protection. The operations contractor $(\mathrm{OC})$ shall ensure that program, as a minimum, addresses institutional safety programs and the key program elements identified in Section 5.1.2.

\subsubsection{Program Key Elements}

The program key elements include the following:

A work development and authorization process that identifies and addresses potential worker hazards and appropriate controls. This process shall be capable addressing significant hazards not specifically addressed by institutional safety programs.

Prohibit facility worker access in or near the 221B Canyon Building without proper controls when any of the conditions identified below exist.

Prohibit facility worker access near the deactivated/retired filter vaults when the following Condition B exists, unless proper approval has been acquired from the appropriate authority and a work plan is established that recognizes the hazards.

Condition A: Snowfall and/or Volcanic Ashfall is building up on the canyon building roof to levels approaching the levels described in the respective B Plant S\&M Phase SAR accident analysis.

Condition B: An earthquake of or near the magnitude of the DBE of $0.12 \mathrm{~g}$ has occurred.

Condition C: The canyon exhaust system is not operating.

Condition D: The surveillance lighting system is not operating.

\subsubsection{Applicability}

This program applies to all activities conducted within the B Plant facility. 
HNF 4243 Rev. 0

\subsection{MANAGEMENT PROGRAMS}

\subsubsection{Requirement for Management Programs}

The operating contractor shall establish, implement and maintain programs as required by the approved authorization basis documents. These programs shall, as a minimum, address those identified in the Program Key Elements Section below. However, other programs identified in the authorization basis documents also constitute programmatic commitments to the DOE.

\subsubsection{Program Key Elements}

The following programs are required as part of this administrative control, other programs are required by commitment in the authorization basis documents:

- A training program to establish and maintain a qualified and trained staff to implement and conduct the commitments explicitly and implicitly expressed in the B Plant S\&M Phase SAR and the TSR document. This includes performing the S\&M activities; maintaining the administrative and safety programs; managing the safety/authorization basis; and complying with the B Plant S\&M Phase SAR and TSR document commitments.

- A fire protection program that implements requirements/recommendations of the fire hazards analysis (FHA) and maintains the FHA current in accordance with DOE requirements.

- A radiological protection program to keep personnel exposures as low as reasonably achievable (ALARA).

- An occupational safety program including industrial hygiene and occupational safety program elements, including the life safety code requirements specified in the FHA.

- A work control program to ensure that work performed has been evaluated for hazards; controls are identified and implemented; and that the work is authorized and conducted in accordance with the safety authorization basis.

- A USQ program to ensure that proposed changes, tests/experiments, and discoveries are evaluated as appropriate to determine their potential impact to the authorization basis.

- An excavation program to ensure the safety of the facility and personnel prior to any excavation within the B Plant area. 
- A nuclear program to maintain the safety authorization basis (SAB) documents valid and current, and to maintain implementation of the SAB. This program shall address maintaining authorization basis interfaces (ABI) between the B Plant facility, authorization basis, and operating organization and interfacing facilities, authorization bases, and operating organizations. In particular, the B Plant ABI program shall address interfaces with the Waste Encapsulation and Storage Facility (WESF) and other interfacing facilities. Specifically, the structural integrity of the B Plant canyon building west endwall, which is adjacent to WESF, shall be monitored, tracked, and trended. Every two years the USQ process shall by used to evaluate the impacts of potential endwall structural integrity changes on assumptions and qualities relied upon in both the B Plant and the WESF authorization bases.

- A program to monitor the B Plant SSCs for structural integrity degradation. This program shall provide for tracking and trending degradation data and provide additional consideration for areas with contamination or other hazards that could negatively impact the facility mission and/or operating commitments. This program shall ensure that, for portions of structures with known structural integrity weaknesses/vulnerabilities, the degree of surveillance is consistent with the vulnerability. Potential structural vulnerabilities are noted in Section 3.3.2.3.1 in the SAR.

- A configuration control program to ensure the configuration is maintained consistent with the authorization basis. The $221 \mathrm{~B}$ roofing membrane shall be inspected annually until a new roofing membrane is installed and is fully funtional.

\subsubsection{Applicability}

This administrative control applies to all activities conducted within the B Plant facility.

\subsection{OPERATIONS EXPECTATIONS/PROGRAMS}

\subsubsection{Requirement for Operations Expectations/Programs}

The operating contractor shall establish, implement and maintain surveillance and maintenance programs for the B Plant facility. These programs shall, as a minimum, include formal procedures and a tracking and trending program that addresses the items identified in the program key elements section below.

\subsubsection{Program Key Elements}

- Retired Filters Surveillance/Maintenance - the following items shall be performed quarterly, unless otherwise specified: 
1. Monitor the vaults for hydrogen accumulation. Ensure the hydrogen concentration does not exceed the FHA recommended limit of $1 \%$.

2. Monitor the configuration of the passive vent system. Ensure the in-line valves are maintained open. Ensure the earth grade and outer configuration features of the deactivated filters vaults is maintained to preclude water intrusion to the vaults.

3. Monitor the water levels in the retired filters. Perform engineering evaluation to determine corrective actions if water is detected.

4. Annually verify that the passive vent system is not plugged by drawing air through the vent system or by another effective verification method.

- Canyon Exhaust System - the OC shall maintain the canyon exhaust system operable. The OC shall notify RL within 4 hours of detection of a system failure. Additionally, the OC shall notify RL if the system cannot be restored to operation within 96 hours of discovery.

- Canyon Exhaust System HEPA Filter Loading - Maintain the radiation monitor system on the HEPA filters operable. Establish radiation loading limits to ensure workers protection during filter changes.

- Cell 10, TK-10-1 Liquid Level Detection System - Maintain the liquid level detection system operable. Monitor the water level in TK-10-1. Notify the DOE within 72 hours if water is detected in the tank at the $25 \%$ level.

- SSC Maintenance - the OC shall have a program to perform maintenance on the operative and passive SSCs to maintain the safety and risk represented by the safety authorization basis.

- Coverblock Movement - No coverblocks shall be raised or moved without explicit DOE approval.

\subsubsection{Applicability}

This administrative control is applicable to all activities within the B Plant facility. 
HNF 4243 Rev. 0

\subsection{REFERENCES}

BWHC 1999 B Plant Surveillance and Maintenance Phase Safety Analysis Report, HNF-3358, Rev. 0, B\&W Hanford Company, Richland, Washington

DOE 1994

DOE Order 5480.22 Technical Safety Requirements and DOE Standard DOE-STD-3009-94, Preparation Guide for U.S. Department of Energy Nonreactor Nuclear Facility Safety Analysis Reports

FDH 1997

Safety Analysis and Technical Safety Requirements, HNF-PRO700, Rev. 1 